\title{
Structure Revision of Isocereulide A, an Isoform of the Food Poisoning Emetic Bacillus cereus Toxin Cereulide
}

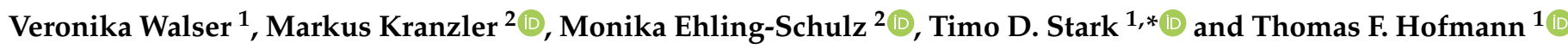 \\ 1 Food Chemistry and Molecular Sensory Science, Technical University of Munich, Lise-Meitner-Str. 34, \\ 85354 Freising, Germany; veronika.walser@tum.de (V.W.); thomas.hofmann@tum.de (T.F.H.) \\ 2 Institute of Microbiology, Department of Pathobiology, University of Veterinary Medicine Vienna, \\ Veterinärplatz 1, 1210 Vienna, Austria; Markus.Kranzler@vetmeduni.ac.at (M.K.); \\ Monika.Ehling-Schulz@vetmeduni.ac.at (M.E.-S.) \\ * Correspondence: timo.stark@tum.de; Tel.: +49-8161-71-2911
}

check for updates

Citation: Walser, V.; Kranzler, M.; Ehling-Schulz, M.; Stark, T.D.; Hofmann, T.F. Structure Revision of Isocereulide A, an Isoform of the Food Poisoning Emetic Bacillus cereus Toxin Cereulide. Molecules 2021, 26, 1360. https://doi.org/10.3390/ molecules 26051360

Academic Editors: Elisa Ovidi and Antonio Tiezzi

Received: 11 February 2021

Accepted: 26 February 2021

Published: 4 March 2021

Publisher's Note: MDPI stays neutral with regard to jurisdictional claims in published maps and institutional affiliations.

Copyright: (c) 2021 by the authors. Licensee MDPI, Basel, Switzerland. This article is an open access article distributed under the terms and conditions of the Creative Commons Attribution (CC BY) license (https:// creativecommons.org/licenses/by/ $4.0 /)$.

\begin{abstract}
The emetic Bacillus cereus toxin cereulide presents an enormous safety hazard in the food industry, inducing emesis and nausea after the consumption of contaminated foods. Additional to cereulide itself, seven structurally related isoforms, namely the isocereulides A-G, have already been elucidated in their chemical structure and could further be identified in B. cereus contaminated food samples. The newly performed isolation of isocereulide A allowed, for the first time, 1D- and 2D-NMR spectroscopy of a biosynthetically produced isocereulide, revealing results that contradict previous assumptions of an L-O-Leu moiety within its chemical structure. By furthermore applying posthydrolytical dipeptide analysis, amino acid and $\alpha$-hydroxy acid analysis by means of UPLC-ESITOF-MS, as well as MS ${ }^{n}$ sequencing, the structure of previously reported isocereulide A could be corrected. Instead of the $\mathrm{L}-\mathrm{O}$-Leu as assumed to date, one L-O-Ile unit could be verified in the cyclic dodecadepsipeptide, revising the structure of isocereulide A to [(D-O-Leu-D-Ala-L-O-Val-L-Val) ${ }_{2}$ (DO-Leu-D-Ala-L-O-Ile-L-Val)].
\end{abstract}

Keywords: B. cereus; isocereulide(s); structure elucidation; UPLC-MS; NMR spectroscopy; $\mathrm{MS}^{\mathrm{n}}$ sequencing

\section{Introduction}

The ubiquitous, endospore-forming, facultative anaerobe bacterium Bacillus cereus [1] is commonly known as a food-borne pathogen, causing, among others, emesis in consequence of the production of its emetic toxin cereulide (1), which is inert to a wide range of environmental parameters such as temperature, $\mathrm{pH}$ values, and enzymes [2-4]. The characteristic dodecadepsipeptide structure of cereulide (1) is composed of the three times circularly repeating tetradepsipeptide unit L-O-Val-L-Val-D-O-Leu-D-Ala, leading to a rectangular cylindrical shape [5-8].

This complex three-dimensional dodecadepsipeptide structure is biosynthetically assembled by nonribosomal peptide synthetases (NRPSs), designated CesNRPS [9]. The CesNRPS genes, which are located on a virulence megaplasmid pXO1 $[10,11]$, are organized as an operon. Apart from the structural cereulide synthetase genes $\operatorname{ces} A$ and $\operatorname{ces} B$, the ces gene locus comprises a phosphopantheteintransferase involved in the activation of the NRPS machinery, a type II thioesterase with a proofreading function and an ABC transporter, recently shown not only to be involved in cereulide export but also directly in cereulide biosynthesis [12-14]. A peptidyl carrier protein (PCP)-coupled D-O-Leu-D-Ala didepsipeptide intermediate is generated by CesA with an in situ reduced D-Leu moiety coupled to D-Ala. Analogously, CesB assembles one in situ reduced L-Val unit with L-Val to form the corresponding L-O-Val-L-Val intermediate $[15,16]$. Cereulide $\mathbf{( 1 )}$ biosynthesis then takes place over a generated L-O-Val-L-Val-D-O-Leu-D-Ala-PCP-coupled intermediate [8] or via the trimerization and macrocyclization of an L-O-Val-L-Val-D-O-Leu-D-Ala intermediate 
by the thioesterase (TE)-dependent CesTE. The latter hypothesis aligns the biosynthesis pathway with the structurally similar toxin valinomycin $[17,18]$.

Next to cereulide (1), a wide chemodiversity of structural homologs have been reported to be present in all emetic $B$. cereus strains or have been synthetically produced, and moreover, the naturally occurring isocereulides A-G were identified in their structure [19-21]. The natural isocereulides, which are produced simultaneously by the CesNRPS, are thought to be formed by one single misincorporation of an $\alpha$-hydroxy acid or an $\alpha$-amino acid by the subunits A1 and A2 of CesA or CesB [18].

The highly cytotoxic isocereulide A (2) was reported to hold one misincorporation in an $\alpha$-hydroxy acid moiety and thus differing from cereulide (1) by implementing one L-OLeu instead of one $\mathrm{L}-\mathrm{O}-\mathrm{Val}$ unit into its cyclic dodecadepsipeptide structure. Isocereulide A (2) was therefore reported as [(D-O-Leu-D-Ala-L-O-Val-L-Val) $)_{2}$ (D-O-Leu-D-Ala-L-O-LeuL-Val)] [20]. In carrying on the research on cereulide chemodiversity [20] and further investigating the existence of isocereulide variants, a discrepancy in the structure of isocereulide A reported to date was revealed. 1D- and 2D-NMR spectroscopic experiments shed light on a different $\alpha$-hydroxy acid substitution. After full structure characterization of the aforementioned isocereulide by means of UPLC-TOF-MS experiments, ion-trap MS ${ }^{\mathrm{n}}$ sequencing, posthydrolytic dipeptide, and enantioselective amino acid analysis, as well as further structure investigation regarding the $\alpha$-hydroxy acid composition, a corrected chemical structure could be elucidated, and thus, the chemical structure of isocereulide A (2) was revised.

\section{Results and Discussion}

\subsection{Mass Spectrometric Characterization and Isolation of Cereulide (1) and Isocereulide A (2)}

Next to cereulide $\left(\mathbf{1} ; \mathrm{m} / \mathrm{z}\right.$ 1170.7125, $\left.\left[\mathrm{M}+\mathrm{NH}_{4}\right]^{+}\right)$, isocereulide A $(2 ; \mathrm{m} / \mathrm{z} 1184.7281$, $\left[\mathrm{M}+\mathrm{NH}_{4}\right]^{+}$) was isolated to allow structure elucidation via UPLC-ESI-TOF-MS and 1Dand 2D-NMR spectroscopy. Cereulide (1) and isocereulide A (2), isolated from cell material originating from a culture of the B. cereus strain F4810/72, were traced in the following semi-preparative HPLC-fractions: cereulide (1; Fraction 8), isocereulide A (2; Fraction 9) (Supplementary Materials, Figure S1B). 1 and 2, respectively, were then purified from the given fractions via analytical HPLC.

In accordance with the recently reported structure for isocereulide A (2) [20], a mass of $m / z 1184.7281$ for the $\left[\mathrm{M}+\mathrm{NH}_{4}\right]^{+}$pseudomolecular ion was observed in UPLC-ESI ${ }^{+}$-TOFMS measurements, varying +14 Da from the $\left[\mathrm{M}+\mathrm{NH}_{4}\right]^{+}$adduct of cereulide $(\mathrm{m} / z$ 1170.7125) (Supporting Information, Figure S2, Table S1), resulting in an elemental composition of $\mathrm{C}_{58} \mathrm{H}_{102} \mathrm{~N}_{7} \mathrm{O}_{18}$, and indicating the addition of one methylene group compared to $\mathbf{1}^{\prime} \mathrm{s}$ structure.

In comparison to the amino and $\alpha$-hydroxy acid composition of cereulide (1) $(3 \times$ Ala, $3 \times \mathrm{Val}, 3 \times \mathrm{O}$-Leu, $3 \times \mathrm{O}$-Val), one of the amino acids or $\alpha$-hydroxy acids present in the structure of 2 was likely exchanged by a 14 Da heavier homologous unit, as indicated by the correspondingly detected $\mathrm{m} / \mathrm{z}$ for isocereulide A (2; $\mathrm{m} / \mathrm{z}$ 1184.7281). Reference [20] suggested an exchange of one L-O-Val by one L-O-Leu unit, determined by alkaline hydrolysis of the isolated compound to give dipeptide units, followed by a comparison with synthesized dipeptide references. Additionally, further acidic hydrolysis on the gained dipeptide intermediates was performed to yield single amino acids and $\alpha$-hydroxy acids, whereof the amino acids were consequently derivatized and mass-spectrometrically analyzed against treated alike enantiopure references to elucidate their corresponding stereo configuration.

\section{2. $D$ - and $2 D-N M R$ Spectroscopy of 2}

The isolation of isocereulide A (2) allowed, for the first time, 1D- and 2D-NMR characterization of a natural isocereulide, originating from B. cereus samples. In direct comparison to the ${ }^{1} \mathrm{H}-\mathrm{NMR}$ spectrum of isocereulide A (2) (Figure 1d) to the ${ }^{1} \mathrm{H}-\mathrm{NMR}$ spectrum of cereulide (1) (Figure 1a), an exchange of one L-O-Val moiety can be concluded, as indicated by the loss of intensity of the corresponding signals (Figure 1d, C-H (8a) 
$\delta=2.55 \mathrm{ppm} ; \mathrm{C}-\mathrm{H}(8) \delta=5.43 \mathrm{ppm}$ ) and appearance of new proton signals belonging to the substitute $\alpha$-hydroxy acid (Figure $1 \mathrm{~d}, \mathrm{C}-\mathrm{H}_{2}\left(13 \mathrm{~b}_{1} / \mathrm{b}_{2}\right) \delta=1.40$ and $1.76 \mathrm{ppm} ; \mathrm{C}-\mathrm{H}$ (13a) $\delta=2.30 \mathrm{ppm} ; \mathrm{C}-\mathrm{H}(13) \delta=5.48 \mathrm{ppm}$ ).
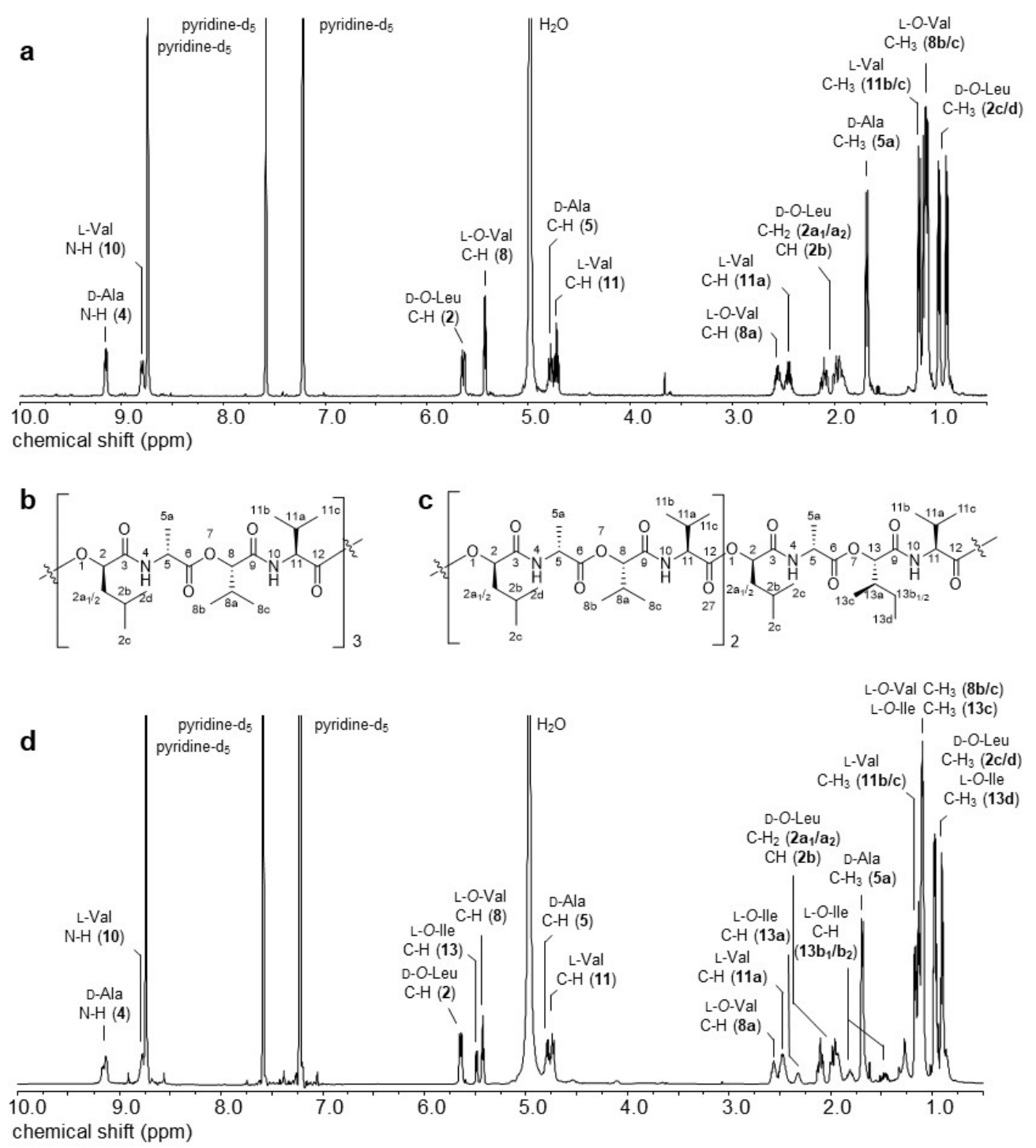

Figure 1. ${ }^{1} \mathrm{H}-\mathrm{NMR}$ spectra and corresponding chemical structures of $(\mathbf{a}, \mathbf{b})$ cereulide $(\mathbf{1})$ and $(\mathbf{c}, \mathbf{d})$ isocereulide A (2).

From the further generated ${ }^{1} \mathrm{H}-{ }^{1} \mathrm{H}-\mathrm{COSY}$-spectrum (Figure 2), the correlation of the single proton signals could be observed, giving, in combination with the signals integrals, the structures of the single amino acids Ala and Val $(\times 3$ each) and $\alpha$-hydroxy acids $O$-Leu $(\times 3)$ and $O$-Val $(\times 2)$, but revealing one additional $O$-Ile moiety. This can be deducted from the correlation of the signals shown in Figure 2, with the key signal being the methine group 13a, exhibiting a correlation to the methyl protons $13 \mathrm{c}$ as well as to the methylene protons $13 b_{1} / b_{2}$. Those novel NMR experiments shed light on the assumption that in fact the isobaric $\alpha$-hydroxy acid $O$-Ile is present in the chemical structure of $\mathbf{2}$ instead of the L-O-Leu moiety reported up to now [20]. 


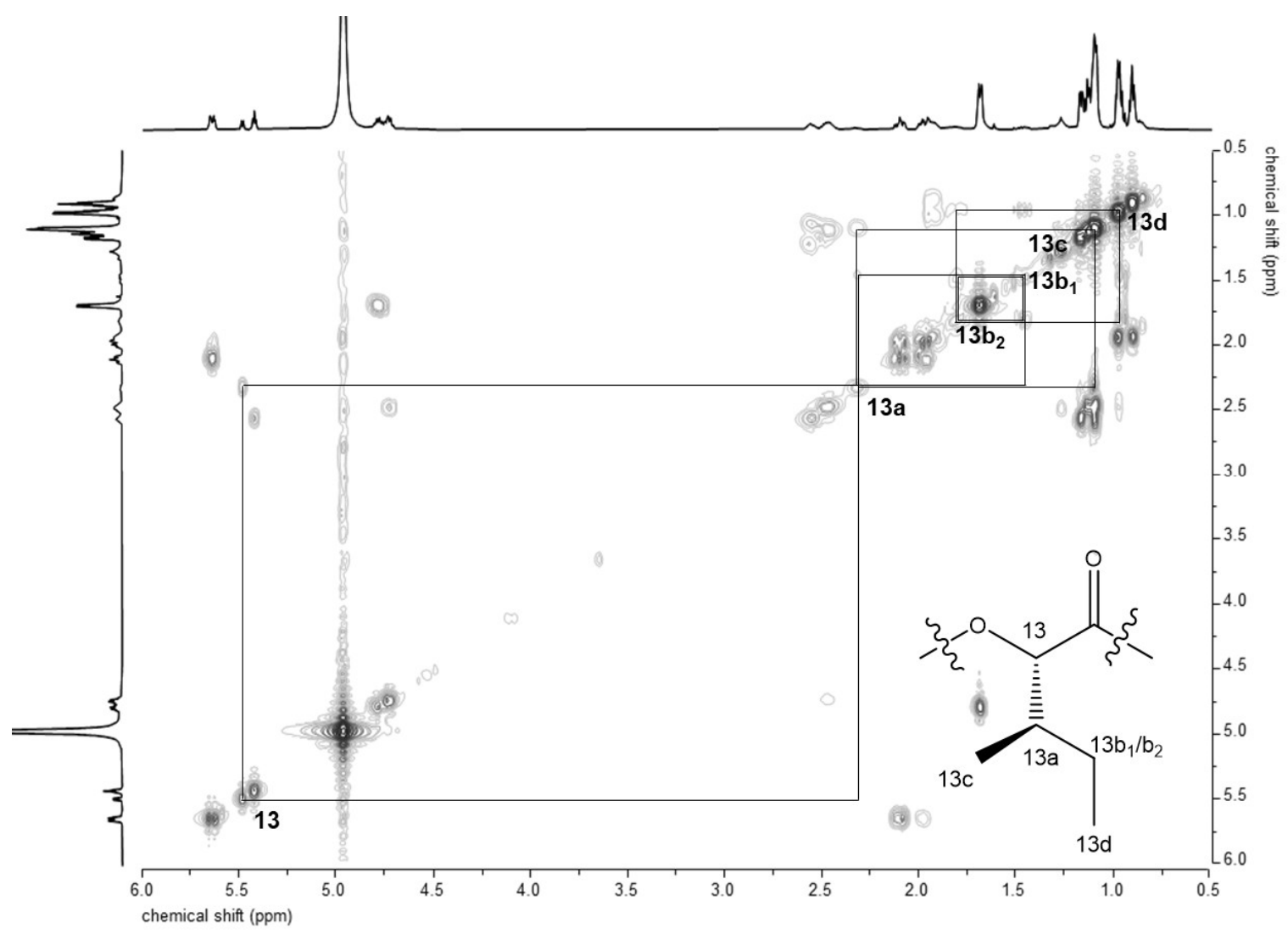

Figure 2. Excerpt of the ${ }^{1} \mathrm{H}_{-}{ }^{1} \mathrm{H}-\mathrm{COSY}-\mathrm{NMR}$ spectrum with highlighted correlations of the $\mathrm{O}$-Ile protons present in the chemical structure of isocereulide A (2).

\subsection{Alkaline Hydrolysis and UPLC-ESI-TOF-MS Analysis of $\mathbf{2}$}

To further support the presence of the O-Ile unit in isocereulide A (2), the sample material was submitted to alkaline hydrolysis to yield dipeptides, followed by comparison to synthesized reference material and acidic hydrolysis with consequent amino acid and $\alpha$-hydroxy acid derivatization, according to the literature protocol $[20,22,23]$. After alkaline hydrolysis, 2 revealed in its UPLC-ESI ${ }^{-}$-TOF-MS analysis, next to D-O-Leu-D-Ala $(\mathrm{m} / \mathrm{z}$ 202.1088, [M-H] $\left.]^{-} ; \mathrm{C}_{9} \mathrm{H}_{16} \mathrm{NO}_{4}\right)$ and L-O-Val-L-Val $\left.(\mathrm{m} / z \text { 216.1240, [M-H] }]^{-} ; \mathrm{C}_{10} \mathrm{H}_{18} \mathrm{NO}_{4}\right)$, one additional dipeptide at $m / z 230.1391[\mathrm{M}-\mathrm{H}]^{-}$, with an empirical elemental composition of $\mathrm{C}_{11} \mathrm{H}_{20} \mathrm{NO}_{4}$ in a ratio of 3:2:1 (Figure 3b). MS e analysis of the questionable dipeptide highlighted a fragmentation pattern concomitant with both $\mathrm{O}$-Leu-Val or O-Ile-Val, exhibiting fragment ions at $m / z 186.1490\left([\mathrm{M}-\mathrm{H}]^{-} ; \mathrm{C}_{10} \mathrm{H}_{20} \mathrm{NO}_{2}\right)$ and $m / z 116.0707\left([\mathrm{M}-\mathrm{H}]^{-} ; \mathrm{C}_{5} \mathrm{H}_{10} \mathrm{NO}_{2}\right)$, respectively (Supporting Information, Figure $\mathrm{S} 4$ ).

By comparing the hydrolysate to the eligible isobaric dipeptides L-O-Leu-L-Val, D-OLeu-L-Val, L-O-Ile-L-Val, and D-O-Ile-L-Val, as well as chromatographic separation of the isomers, the dipeptide at hand was identified (Figure 3). In this chromatographic separation, the L-O-Leu-L-Val dipeptide, recently reported to be present in isocereulide A (2) [20], showed a retention time shift by 0.35 min compared to the dipeptide naturally present in the alkaline hydrolysis of $\mathbf{2}$ (Figure 3d). Only the spiking of L-O-Ile-L-Val exhibited an increase in the peak intensity of the respective dipeptide and showed no visible additional signal (Figure 3c). Thus, of the aforementioned four isobaric dipeptides, uniquely L-O-IleL-Val qualified as the dipeptide at hand in the structure of isocereulide A (2). 

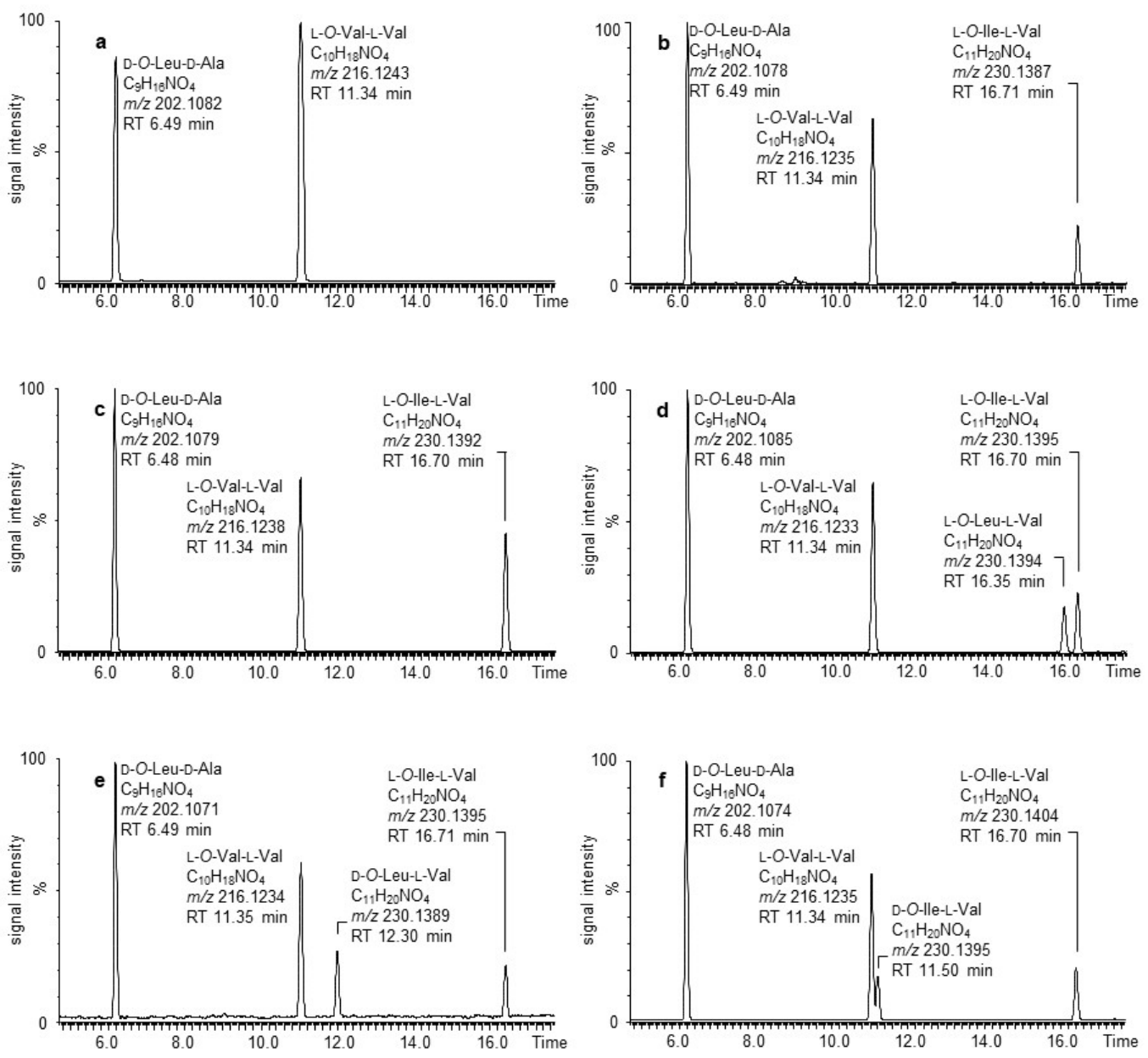

Figure 3. UPLC-ESI--TOF-MS-analyses of alkaline hydrolysates of (a) cereulide (1), (b) isocereulide A (2), (c) 2 spiked with L-O-Ile-L-Val, (d) 2 spiked with L-O-Leu-L-Val, (e) 2 spiked with D-O-Leu-L-Val, and (f) 2 spiked with D-O-Ile-L-Val.

\subsection{Acidic Hydrolysis and Enantioselective Amino Acid and $\alpha$-Hydroxy Acid Analysis of $\mathbf{2}$}

To unequivocally identify the absolute amino acid and $\alpha$-hydroxy acid composition in isocereulide A (2), subsequent acidic hydrolysis, free amino acid analysis according to Reference [20], and, for the first time in an isocereulide, $\alpha$-hydroxy acid analysis were performed. The hydrolysate was analyzed via UPLC-TOF-ESI ${ }^{-}$-MS after enantioselective derivatization of the amino acids and the $\alpha$-hydroxy acids via OPA/IBLC, and S-(+)-MTPA chloride, respectively [22,23], followed by a comparison of accurate $\mathrm{m} / \mathrm{z}$ and retention times of treated alike enantiopure amino acid and $\alpha$-hydroxy acid references.

As a reference sample, $\mathbf{1}$ was treated under the same conditions. For the analysis of isoindole-amino acid derivatives from $\mathbf{2}$, fitting well together with the already published data [20], only D- and L-Ala in a ratio of 99.9/0.1 and D- and L-Val in a ratio of 0.1/99.9 could be determined, thus indicating the presence of D-Ala and L-Val as amino acid modules, while L-Ala and D-Val are absent (Supporting Information, Figure S5).

The novel analysis of MTPA- $\alpha$-hydroxy acid esters for 2 revealed the $\alpha$-hydroxy acids D- and L-O-Val in a ratio of 0.1/99.9 and D- and L-O-Leu and L-O-Ile in a ratio of $77.1 / 0.1 / 22.8$, confirming the presence of L-O-Val, D-O-Leu, and also L-O-Ile while at the same time providing evidence for the lack of D-O-Val and L-O-Leu. Additionally, the ratio observed for the $\alpha$-hydroxy acids $\mathrm{D}-\mathrm{O}$-Leu and $\mathrm{L}-\mathrm{O}$-Ile, is in agreement with the theoretically calculated distribution of $75 / 25$. Thus, the dipeptide units D-O-Leu-D-Ala, L-O-Val-L-Val, and L-O-Ile-L-Val could evidently be identified with a ratio of 3:2:1 as the components present in the chemical structure of isocereulide A (2), with L-O-Leu-L-Val not occurring within this structure (Supporting Information, Figure S6). 


\section{5. $M S^{n}$ Sequencing of $\mathbf{2}$}

Due to multiple theoretically possible arrangements of the identified dipeptide modules within the cyclic dodecadepsipeptide structure of the isocereulide, the exact alignment of the entities was determined by means of sequential $\mathrm{MS}^{\mathrm{n}}$ fragmentation. The favored ester cleavage of the depsipeptide structure evoked the formation of a maximum of six theoretically possible isobaric open-chain pseudomolecular ions for isocereulide A, resulting from different possible locations of the ring opening. Thereof, one theoretical dipeptide sequence was selected as a precursor for further fragmentation of resulting intermediates according to the selected dipeptide pattern. (Figure 4, MS ${ }^{\mathrm{n}}$ data pictured in Supporting Information).
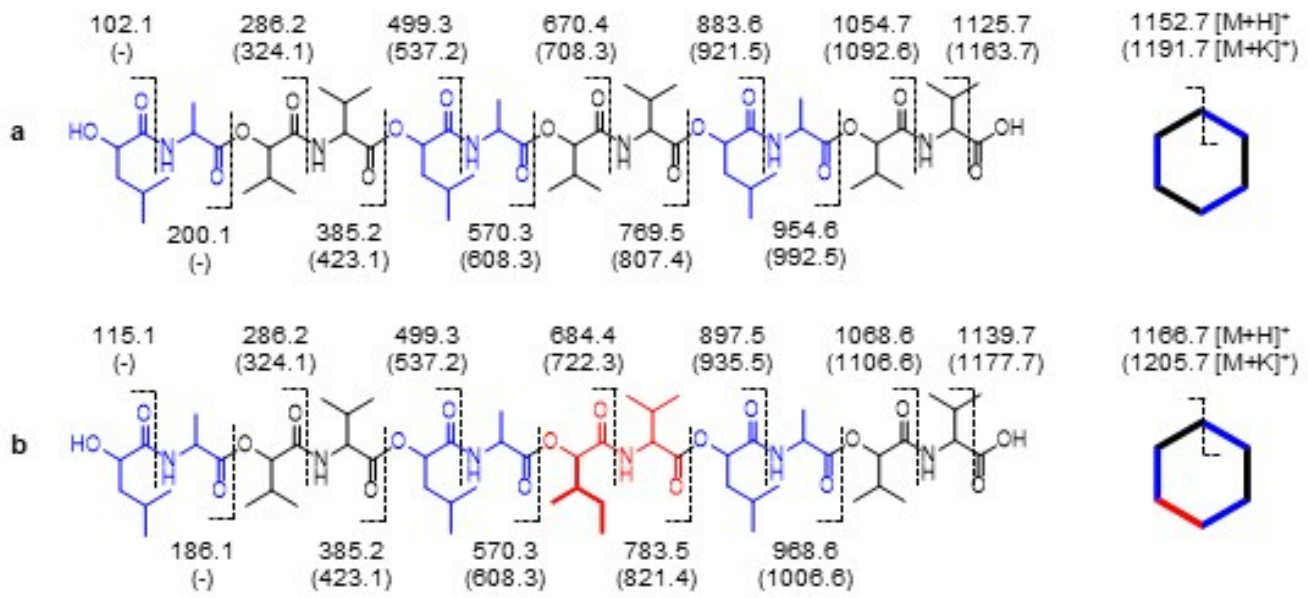

Figure 4. $\mathrm{MS}^{\mathrm{n}}$ sequences of the selected pseudomolecular ions for the structure elucidation of (a) cereulide (1) and (b) isocereulide A (2) (black: L-O-Val-L-Val, blue: D-O-Leu-D-Ala, red: L-O-Ile-L-Val).

In alignment with the already published data on isocereulide A (2) [20], the MS sequencing revealed the $[\mathrm{M}+\mathrm{K}]^{+}$pseudomolecular ions $1205.7 \rightarrow 1006.6 \rightarrow 821.4$ in the MS, $\mathrm{MS}^{2}$, and $\mathrm{MS}^{3}$ scans for 2 indicating the elimination of L-O-Val-L-Val and D-O-Leu-D-Ala. The following $\mathrm{MS}^{4}$ scan then exhibited the key fragment $(821.4 \rightarrow 722.3 / 608.3)$, giving the location of the L-O-Ile-L-Val unit. After that, $\mathrm{MS}^{5}$ and MS ${ }^{6}$ exhibited the loss of D-O-LeuD-Ala followed by L-O-Val-L-Val showing the fragments of $608.3 \rightarrow 423.1 \rightarrow 323.1$, thus confirming the general sequence of the to date reported isocereulide A (2) [20].

\section{Materials and Methods}

\subsection{Chemicals and Samples}

\subsubsection{Chemicals}

The following compounds were commercially obtained: chloroform (anhydrous, $\geq 99 \%$ ), D-(+)-glucose monohydrate, methanol- $d_{4}, N$-isobutyryl-L-cysteine (IBLC), $N, N$ diisopropylethylamine (DIPEA), O-(Benzotriazol-1-yl)- $N, N, N^{\prime}, N^{\prime}$-tetraethyluronium hexafluoro phosphate (HBTU), ortho-phthaldialdehyde (OPA), piperidine, potassium hydroxide $(\mathrm{KOH})$, potassium tetraborate tetrahydrate $\left(\mathrm{B}_{4} \mathrm{~K}_{2} \mathrm{O}_{7} \times 4 \mathrm{H}_{2} \mathrm{O}\right)$, pydridine (anhydrous, $99.8 \%$ ), pyridine- $d_{5},(S)-(-)-2$-hydroxyisocaproic acid (L-O-Leu), and trifluoroacetic acid (reagent plus, 99\%) from Sigma-Aldrich (Steinheim, Germany); Fmoc-L-Val-Wang resin (100-200 mesh each), D- and L-alanine, D- and L-valine, $\mathrm{HCl}(37 \%), \mathrm{N}, \mathrm{N}$-dimethylformamide (DMF), and formic acid (HCOOH) from Merck (Darmstadt, Germany); dichloromethane $\left(\mathrm{CH}_{2} \mathrm{Cl}_{2}\right)$ from Carl Roth (Karlsruhe, Germany); $\mathrm{L}-\alpha$-hydroxyisovaleric acid (L-O-Val), D$\alpha$-hydroxyisovaleric acid (D-O-Val), D- $\alpha$-hydroxyisocaproic acid (D-O-Leu) from Bachem (Bubendorf, Switzerland); and (2S,3S)-2-hydroxy-3-methylpentanoic acid (L-O-Ile) from Interchim (Montluçon Cedex, France); (2R,3R)-2-hydroxy-3-methylpentanoic acid (D-O-Ile) from SIA Enamine (Riga, Latvia) and $(S)-(+)-\alpha$-methoxy- $\alpha$-trifluoromethylphenylacetic acid chloride (MTPA) from TCI Deutschland GmbH (Eschborn, Germany). 
$\mathrm{H}_{2} \mathrm{O}$ for chromatography was purified with a Milli-Q Reference A+System (Merck), solvents used were of HPLC or LC-MS grade (J.T. Baker, Deventer, Holland).

\subsubsection{B. cereus Culture and Growth Conditions}

For the biofermentative generation of cereulide and isocereulide $\mathrm{A}$, cultures of the emetic B. cereus strain F4810/72 were prepared as described previously [24]. In brief, $3 \mathrm{~mL}$ of lysogeny broth (LB) were inoculated with B. cereus strain F4810/72 and incubated for $16 \mathrm{~h}$ at $30{ }^{\circ} \mathrm{C}$ while shaking (120 rpm). These precultures were used for kinetic inoculation of $100 \mathrm{~mL}$ LB medium in rotary flasks with $10^{3} \mathrm{cfu} / \mathrm{mL}$. Cultures were incubated with shaking (120 rpm) at $30^{\circ} \mathrm{C}$ for $24 \mathrm{~h}$. After centrifugation ( $\left.8000 \mathrm{rpm}, 2 \mathrm{~min}\right)$ and discarding of the supernatant, the remaining cell pellets were autoclaved $\left(121^{\circ} \mathrm{C}, 15 \mathrm{~min}\right)$. The pellets were stored at $-20^{\circ} \mathrm{C}$ until further use.

\subsubsection{Solvent Extraction and Toxin Isolation}

The pellets of strains F4810/72 were thawed and extracted with EtOH $(3 \times 30 \mathrm{~mL})$ by shaking for $1 \mathrm{~h}$ (400 rpm, RT). The ethanolic extracts were centrifuged (4000 rpm; $10 \mathrm{~min})$, their supernatants membrane filtrated $(0.2 \mu \mathrm{m}$; PTFE; Phenomenex, Aschaffenburg, Germany) to remove remaining cell material, all liquids combined, and the solvent reduced to one-fifth under low pressure by means of a rotary evaporator. The concentrated ethanolic extract was stored at $-20^{\circ} \mathrm{C}$ until further use.

The reduced ethanolic extract was diluted with $\mathrm{H}_{2} \mathrm{O}(1: 10)$ and prefractionated via C18 SPE cartridges (60 mL, 10 g, Chromabond, Macherey-Nagel, Düren, Germany) according to Reference [20], with preconditioned columns using $\mathrm{MeOH}(30 \mathrm{~mL}), \mathrm{MeOH} / \mathrm{H}_{2} \mathrm{O}$ $(50 / 50 ; v / v ; 30 \mathrm{~mL})$ and $\mathrm{H}_{2} \mathrm{O}(60 \mathrm{~mL})$. To enrich the desired compounds, $15 \mathrm{~mL}$ of the prepared cell extract was applied, eluted through the column, and flushed with $\mathrm{H}_{2} \mathrm{O}(20 \mathrm{~mL})$. The process was repeated five times. After the final sample application, the columns were rinsed with $\mathrm{MeOH} / \mathrm{H}_{2} \mathrm{O}(70 / 30 ; v / v ; 60 \mathrm{~mL})$, dried under reduced pressure using a vacuum pump (30 min), and finally, the target molecules eluted with $\mathrm{MeOH}(60 \mathrm{~mL})$. Obtained methanolic fractions were combined, the solvent removed under reduced pressure via rotary evaporator to approx. $150 \mathrm{~mL}$, and stored at $-20{ }^{\circ} \mathrm{C}$ until further use for compound isolation.

Semi-preparative HPLC was performed as reported recently [20] on a PrepStar system (Varian, Darmstadt, Germany), consisting of two HPLC pumps (model SD-1), a twowavelength UV detector (Prostar 325), and a fraction collector (model 701), equipped with a $250 \times 10 \mathrm{~mm}, 4 \mu \mathrm{m}, 90 \AA$ A Jupiter Proteo column (Phenomenex, Aschaffenburg, Germany). The effluent was monitored at $220 \mathrm{~nm}$, while chromatography was performed at $4.2 \mathrm{~mL} /$ min using $\mathrm{H}_{2} \mathrm{O}$ (Solvent $\mathrm{A}$ ) and $\mathrm{MeOH}$ (Solvent $\mathrm{B}$ ), starting with $85 \%$ B for $1 \mathrm{~min}$, increasing to $92 \%$ B in $15 \mathrm{~min}$, holding $92 \% \mathrm{~B}$ for $9 \mathrm{~min}$, increasing to $100 \% \mathrm{~B}$ within $1 \mathrm{~min}$, holding $100 \%$ B for $9 \mathrm{~min}$, and decreasing to $85 \%$ B in $1 \mathrm{~min}$, followed by equilibration for $2 \mathrm{~min}$. The eluate was separated into 10 fractions (Supporting Information; Figure S1B), and respective liquids were combined. After solvent removal by using a rotary evaporator, water $(15 \mathrm{~mL})$ was added, and the fractions were freeze-dried twice and stored until further fractionation at $-20^{\circ} \mathrm{C}$.

The obtained HPLC-fractions were screened for cereulide (1) and the isocereulides A-G by means of an UPLC-TOF-MS system Synapt G2-S (Waters, Manchester, UK) in the positive electrospray mode equipped with a $2.1 \times 150 \mathrm{~mm}, 1.7 \mu \mathrm{m}$, BEH-C18 column (Waters, Manchester, UK) at a flowrate of $0.4 \mathrm{~mL} / \mathrm{min}$ at $45^{\circ} \mathrm{C}$ using aqueous $\mathrm{HCOOH}$ $(0.1 \%)$ as Solvent $\mathrm{A}$ and $\mathrm{MeCN}$ with $\mathrm{HCOOH}(0.1 \%)$ as Solvent B. Elution was started at $93 \% \mathrm{~B}$ and increased to $100 \% \mathrm{~B}$ in $4 \mathrm{~min}$, held at $100 \% \mathrm{~B}$ for $2 \mathrm{~min}$, followed by decreasing to $93 \%$ in $0.1 \mathrm{~min}$, and holding at $93 \% \mathrm{~B}$ for $0.9 \mathrm{~min}$.

Analytical purification was performed on an HPLC system (Jasco, Groß-Umstadt, Germany) consisting of an HPLC-pump (PU 2080 Plus), a degasser (DG-2080-53 3-LineDegasser), a DAD/UV detector (MD-2010 Plus), coupled with an autosampler (AS-2055 Plus) and equipped with a $250 \times 4.6 \mathrm{~mm}$, Jupiter ${ }^{\circledR} 4 \mu \mathrm{m}$ Proteo $90 \AA ̊$ (Phenomenex, Aschaf- 
fenburg, Germany). Chromatography was performed at $1 \mathrm{~mL} / \mathrm{min}$ with $\mathrm{H}_{2} \mathrm{O}$ (Solvent A) and $\mathrm{MeOH}$ (Solvent B), starting at $80 \%$ B for $3 \mathrm{~min}$, increasing to $92 \%$ B within $10 \mathrm{~min}$, holding isocratically for $17 \mathrm{~min}$, increasing to $100 \% \mathrm{~B}$ within $0.5 \mathrm{~min}$ and staying at $100 \% \mathrm{~B}$ for $1.5 \mathrm{~min}$, decreasing to $80 \% \mathrm{~B}$ within $0.5 \mathrm{~min}$ and finally equilibrating at $80 \% \mathrm{~B}$ for $1.5 \mathrm{~min}$. The effluent was monitored at $220 \mathrm{~nm}$, and eluting substances were collected manually.

\subsubsection{Analysis of Dipeptides, Resulting of Alkaline Hydrolysis of $\mathbf{1}$ and $\mathbf{2}$}

Following Reference [20], the purified cereulide (1) and isocereulide A (2) ( 500 $\mu \mathrm{g})$, respectively, were dissolved in methanolic $\mathrm{KOH}(1.2 \mathrm{M}, 80 \% \mathrm{MeOH})$, heated to $50{ }^{\circ} \mathrm{C}$ for $2 \mathrm{~h}$. The $\mathrm{pH}$ value was adjusted to $\mathrm{pH}$ 5.0, and the hydrolysates were applied for UPLC-TOF-MS measurement on a Synapt G2-S system (Waters, Manchester, UK), using the spectrometric parameters in the negative electrospray ionization mode, as reported recently [20]. Chromatography was performed on a $2.1 \times 150 \mathrm{~mm}, 1.7 \mu \mathrm{m}, \mathrm{BEH}-\mathrm{C} 18$ column (Waters, Manchester, UK), using aqueous $\mathrm{HCOOH}(0.1 \%)$ as Solvent A and a mixture of $\mathrm{MeCN} / \mathrm{HCOOH}(99.9 / 0.1 ; v / v)$ as Solvent $\mathrm{B}$ at a flowrate of $0.4 \mathrm{~mL} / \mathrm{min}$ at $45{ }^{\circ} \mathrm{C}$, started at $10 \% \mathrm{~B}$ for $1 \mathrm{~min}$, increased to $20 \% \mathrm{~B}$ in $14 \mathrm{~min}$, to $30 \% \mathrm{~B}$ in $5 \mathrm{~min}$, and to $100 \% \mathrm{~B}$ in $0.5 \mathrm{~min}$. It was then kept at $100 \% \mathrm{~B}$ for $1 \mathrm{~min}$, decreased to $10 \% \mathrm{~B}$ within $0.5 \mathrm{~min}$, and equilibrated at $10 \% \mathrm{~B}$ for $1 \mathrm{~min}$.

\subsubsection{Acidic Hydrolysis and Analysis of Amino Acids as Well as $\alpha$-Hydroxy Acids}

To determine the stereochemistry of the single amino acids and $\alpha$-hydroxy acids contained in the analyzed dipeptides forming the isocereulide structure, aliquots $(\sim 200 \mu \mathrm{L})$ of the alkaline hydrolysates of $\mathbf{1}$ and $\mathbf{2}$, respectively, were further used for acidic hydrolysis $\left(3 \mathrm{~mL} \mathrm{HCl}, 6 \mathrm{M}, 24 \mathrm{~h}, 110^{\circ} \mathrm{C}\right)$, adjusted to $\mathrm{pH} 7.0$ with $\mathrm{KOH}(1 \mathrm{M})$, and freeze-dried [20]. The lyophilisates were extracted with MeCN (5 mL), centrifuged (4200 rpm, $10 \mathrm{~min})$, and separated into the amino acid containing the salt residue and the $\alpha$-hydroxy acid containing liquid phase. Remaining $\mathrm{MeCN}$ was evaporated under a stream of nitrogen. In the following, both aliquots of the acidic hydrolysate of $\mathbf{1}$ and $\mathbf{2}$ were put to enantioselective derivatization. Therefore, the derivatization of the amino acids in cereulide (1) and isocereulide A (2), as well as the corresponding reference amino acids D/L-Ala and D/L-Val (50 $\mu \mathrm{mol}$ each), was performed using OPA and IBLC [22] followed by SPE purification considering Reference [20]. The methanolic eluate gained via SPE was analyzed via UPLCTOF-MS, applying the same mass spectrometric parameters as described for the alkaline hydrolysis. Chromatography was performed at $45^{\circ} \mathrm{C}$ and a flowrate of $0.4 \mathrm{~mL} / \mathrm{min}$ on a $2.1 \times 150 \mathrm{~mm}, 1.7 \mu \mathrm{m}$, BEH-C18 column (Waters, Manchester, UK) with aqueous $\mathrm{HCOOH}$ $(0.1 \%)$ as Solvent $\mathrm{A}$, and a mixture of $\mathrm{MeCN} / \mathrm{HCOOH}(99.9 / 0.1 ; v / v)$ as Solvent B, while starting the gradient at 30\% B for $3 \mathrm{~min}$, increasing to $33 \% \mathrm{~B}$ in $3 \mathrm{~min}$, to $50 \% \mathrm{~B}$ in $6 \mathrm{~min}$, and to $100 \% \mathrm{~B}$ in $1 \mathrm{~min}$, followed by holding $100 \%$ B for $1 \mathrm{~min}$, decreasing to $30 \%$ B within $0.5 \mathrm{~min}$, and ending with an equilibration at $30 \% \mathrm{~B}$ for $1.5 \mathrm{~min}$. The mass spectrometric data, obtained during the analysis of the amino acid isoindole derivatives, was summarized in the following: D-Ala derivative: accurate mass: $\mathrm{m} / \mathrm{z} 377.1180, \Delta$ (ppm): +2.4 ; calcd: $\mathrm{m} / \mathrm{z}$ $377.1171\left(\mathrm{C}_{18} \mathrm{H}_{21} \mathrm{~N}_{2} \mathrm{O}_{5} \mathrm{~S}\right)$; L-Ala derivative: accurate mass: $m / z$ 377.1181, $\Delta$ (ppm): +2.7; calcd: $m / z 377.1171\left(\mathrm{C}_{18} \mathrm{H}_{21} \mathrm{~N}_{2} \mathrm{O}_{5} \mathrm{~S}\right)$; D-Val derivative: accurate mass: $m / z$ 405.1489, $\Delta$ (ppm): +1.2; calcd: $m / z 405.1484\left(\mathrm{C}_{20} \mathrm{H}_{25} \mathrm{~N}_{2} \mathrm{O}_{5} \mathrm{~S}\right)$; L-Val derivative: accurate mass: $m / z 405.1492$, $\Delta$ (ppm): +2.0; calcd: $m / z 405.1484\left(\mathrm{C}_{20} \mathrm{H}_{25} \mathrm{~N}_{2} \mathrm{O}_{5} \mathrm{~S}\right)$.

Enantioselective derivatization of $\alpha$-hydroxy acids was performed applying $S$-(+)MTPA chloride, in accordance with Reference [23]. Pydridine (anhydrous, $1 \mu \mathrm{L}$ ) was added to enantiomeric pure reference acids D/L-O-Val, D/L-O-Leu, and D/L-O-Ile $(\sim 0.5 \mu$ mol each) and the $\alpha$-hydroxy acid containing hydrolysate layer of $\mathbf{1}$ and $\mathbf{2}$, respectively, followed by dissolution of the sample material in anhydrous chloroform $(100 \mu \mathrm{L})$, supplementing $S$-(+)-MTPA chloride $(1 \mu \mathrm{L})$, and stirring for $1 \mathrm{~h}$ at room temperature. The solution was diluted 1:100 with MeCN and applied for UPLC-TOF-MS experiments. MS parameters were identical to those described for the analysis of amino acids with the following solvent gradient: start at 30\% B and hold for $1 \mathrm{~min}$, increase to $50 \% \mathrm{~B}$ in $10 \mathrm{~min}$, to $53 \%$ B within 
$5 \mathrm{~min}$, and to $100 \% \mathrm{~B}$ in $1 \mathrm{~min}$, hold at $100 \% \mathrm{~B}$ for $1 \mathrm{~min}$, decrease in $0.5 \mathrm{~min}$ to $30 \% \mathrm{~B}$, and hold for $1.5 \mathrm{~min}$. The analytical data obtained for the individual $\alpha$-hydroxy acid MTPA esters were the following: $\mathrm{D}-\mathrm{O}-\mathrm{Val}$ derivative: accurate mass: $m / z 333.0949, \Delta$ (ppm): -0.3 ; calcd: $m / z 333.0950\left(\mathrm{C}_{15} \mathrm{H}_{16} \mathrm{~F}_{3} \mathrm{O}_{5}\right)$; L-O-Val derivative: accurate mass: $m / z$ 333.0950, $\Delta$ (ppm): 0.0; calcd: $m / z 333.0950\left(\mathrm{C}_{15} \mathrm{H}_{16} \mathrm{~F}_{3} \mathrm{O}_{5}\right)$; D-O-Leu derivative: accurate mass: $m / z$ 347.1106, $\Delta$ (ppm): 0.0; calcd: $m / z 347.1106\left(\mathrm{C}_{16} \mathrm{H}_{18} \mathrm{~F}_{3} \mathrm{O}_{5}\right)$; L-O-Leu derivative: accurate mass: $m / z$ 347.1108, $\Delta$ (ppm): + 0.6; calcd: $m / z 347.1106\left(\mathrm{C}_{16} \mathrm{H}_{18} \mathrm{~F}_{3} \mathrm{O}_{5}\right)$; D-O-Ile derivative: accurate mass: $m / z$ 347.1106, $\Delta$ (ppm): 0.0; calcd: $m / z 347.1106\left(\mathrm{C}_{16} \mathrm{H}_{18} \mathrm{~F}_{3} \mathrm{O}_{5}\right)$; L-O-Ile derivative: accurate mass: $m / z$ 347.1107, $\Delta$ (ppm): + 0.3; calcd: $m / z 347.1106\left(\mathrm{C}_{16} \mathrm{H}_{18} \mathrm{~F}_{3} \mathrm{O}_{5}\right)$.

\subsection{Technical Data}

\subsubsection{Mass Spectrometry}

High-resolution mass spectrometry (UPLC-ESI-TOF-MS) was performed on a Waters Synapt G2-S HDMS spectrometer combined with an Acquity UPLC core system (Waters, Manchester, UK), composed of a binary solvent manager, sample manager, and column. For system operation and data processing, the MassLynx 4.1 SCN 851 Software (Waters, Manchester, UK) was exercised. All data were corrected via lock mass referencing on the pentapeptide leucine enkephalin (Tyr-Gly-Gly-Phe-Leu, $m / z$ 556.2771, $[\mathrm{M}+\mathrm{H}]+$ and 554.2615, [M-H]-), which was supplied as $2 \mathrm{ng} / \mu \mathrm{L}$ solved in MeCN/0.1\% HCOOH (1/1, $v / v)$. Scan time for lock mass was set to $0.3 \mathrm{~s}$, an interval of $10 \mathrm{~s}$, and 3 scans to average, with a mass window of $\pm 0.5 \mathrm{Da}$. Calibration of the Synapt G2-S was performed in the range from $\mathrm{m} / \mathrm{z} 50$ to 1200 with a solution of sodium formate $(5 \mathrm{mmol} / \mathrm{L})$ in 2-propanol $/ \mathrm{H}_{2} \mathrm{O}$ $(9 / 1, v / v)$. Source parameters were applied according to Reference [20].

MS $^{n}$ measurements were carried out on a Bruker Daltonics HCTultra PTM Discovery System (Bruker Daltonics Billerica, MA, USA), following the literature protocol [20].

\subsubsection{Nuclear Magnetic Resonance Spectroscopy}

Nuclear magnetic resonance (NMR) spectra were recorded using a $400 \mathrm{MHz}$ Avance III spectrometer with a Broadband Observe BBFO plus and a $500 \mathrm{MHz}$ Avance NEO spectrometer with a cryoprobe CTCI $\left({ }^{1} \mathrm{H} /{ }^{13} \mathrm{C} /{ }^{15} \mathrm{~N}\right)$ (Bruker, Rheinstetten, Germany). The chemical shift was referenced to the solvent signal, $\mathrm{MeOH}-d_{4}$ and pyridine- $d_{5}$, respectively. Data processing and evaluation were performed using the Topspin Software Version 4.0.7 (Bruker, Rheinstetten, Germany) (Figure 5).

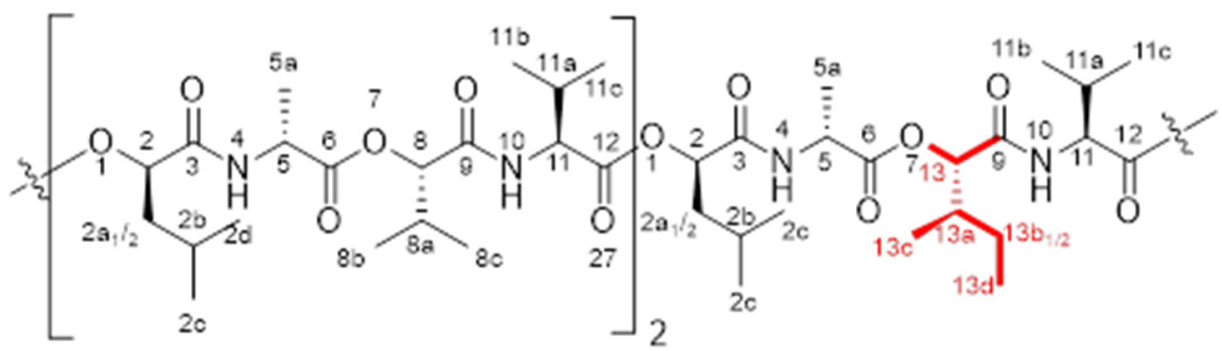

Figure 5. Open-chain chemical structure of isocereulide A (2).

${ }^{1} \mathrm{H}-\mathrm{NMR}, \mathrm{COSY}\left[500 \mathrm{MHz}\right.$, pyridine- $\left.d_{5}, 298 \mathrm{~K}\right]: \delta(\mathrm{ppm}) 0.90[\mathrm{~d}, 9 \mathrm{H}, J=6.18 \mathrm{~Hz}$, $\left.\mathrm{H}_{3}-\mathrm{C}(2 \mathrm{c})\right], 0.97$ [m, 12H, $\left.\mathrm{H}_{3}-\mathrm{C}(2 \mathrm{~d}, 13 \mathrm{~d})\right], 1.07-1.22$ [m, 33H, $\left.\mathrm{H}_{3}-\mathrm{C}(8 \mathrm{~b}, 8 \mathrm{c}, 11 \mathrm{~b}, 11 \mathrm{c}, 13 \mathrm{c})\right], 1.38-$ $1.50\left[\mathrm{~m}, 1 \mathrm{H}, \mathrm{H}-\mathrm{C}\left(13 \mathrm{~b}_{1}\right)\right], 1.68[\mathrm{dd}, 9 \mathrm{H}, J=6.2 \mathrm{~Hz}, \mathrm{H}-\mathrm{C}(5 \mathrm{a})], 1.72-1.83\left[\mathrm{~m}, 1 \mathrm{H}, \mathrm{H}-\mathrm{C}\left(13 \mathrm{~b}_{2}\right)\right]$, 1.88-2.03 [m, 6H, H-C $\left(2 \mathrm{a}_{1}, 2 \mathrm{~b}\right)$ ], 2.06-2.16 [m, 3H, H-C (2a $\left.\mathrm{a}_{2}\right)$ ], 2.27-2.33 (m, 1H, H-C(13a)], 2.38-2.50 [m, 3H, H-C(11a)], 2.50-2.61 [m, 2H, H-C(8a)], 4.69-4.75 [dd, 3H, J = 7.5, $15.2 \mathrm{~Hz}$, $\mathrm{H}-\mathrm{C}(11)$ ], 4.75-4.82 [quint, 3H, $J=6.6,13.3 \mathrm{~Hz}, \mathrm{H}-\mathrm{C}(5)], 5.43$ [dd, 2H, $J=4.6,8.9 \mathrm{~Hz}, \mathrm{H}-\mathrm{C}(8)$ ], $5.48[\mathrm{~d}, 1 \mathrm{H}, J=5.0 \mathrm{~Hz}, \mathrm{H}-\mathrm{C}(13)], 5.62-5.67$ [m, 3H, H-C(2)], 8.76-8.80 [m, 3H, H-N(10)], 9.15 [dd, 3H, H-N(4)]. DEPT135, HSQC, HMBC [125 MHz, pyridin- $\left.d_{5}, 298 \mathrm{~K}\right]: \delta(\mathrm{ppm})$ $11.6[\mathrm{C}(13 \mathrm{~d})], 15.5[\mathrm{C}(13 \mathrm{c})], 17.18$ [C(5a)], 17.24 [C(13b)], $17.5[\mathrm{C}(8 \mathrm{~b})], 19.06 / 19.10 / 19.5$ [C(8c/11b/11c)], 21.4 [C(2c)], $23.4[C(2 d)], 24.79[C(2 b)], 24.84[C(13 b)], 30.0[C(11 a)], 30.4$ 
[C(11a)], 30.5 C[(11a)], 31.2 [C(8a)], 37.4 [C(13a)], 41.4 [C(2a)], 49.71 [C(5)], 49.74 [C(5)], 49.77 [C(5)], 59.18 [C(11)], 59.25 [C(11)], 59.28 [C(11)], 73.3 [C(2)], 78.5 [C(13)], 79.0 [C(8)], 170.4 [C(9)], 170.6 [C(9)], 170.9 [C(9)], 171.1 [C(3)], 171.26 [C(3)], 171.34 [C(3)].

\section{Conclusions}

The emetic B. cereus toxin cereulide and its isocereulides comprise a complex, threedimensional dodecadepsipeptide structure [5-8]. For the to date structurally known isocereulides A-E, one amino acid or $\alpha$-hydroxy acid is exchanged, while for isocereulides $\mathrm{G}$ and $\mathrm{F}$ a dipeptide section is switched or replaced. Isocereulide $\mathrm{A}$ in particular was reported as [(D-O-Leu-D-Ala-L-O-Val-L-Val) $)_{2}$ (D-O-Leu-D-Ala-L-O-Leu-L-Val)] beforehand [20], differing from cereulide only by the exchange of one L-O-Val unit by one L-O-Leu moiety. With the investigation of isocereulide $\mathrm{A}$ in this study, for the first time, 1D- and 2D-NMR techniques were employed to investigate a natural isocereulide and by additional UPLCESI-TOF-MS dipeptide, amino acid and $\alpha$-hydroxy acid analysis, and $\mathrm{MS}^{\mathrm{n}}$ sequencing, the chemical structure of isocereulide A was revised to [(D-O-Leu-D-Ala-L-O-Val-L-Val) 2 (D-OLeu-D-Ala-L-O-Ile-L-Val)].

Supplementary Materials: The following are available online at, Figure S1A: Cyclic structure of cereulide. Figure S1B: Chromatogram of the semi-preparative RP-HPLC separation of the ethanolic extract of B. cereus strain F4810/72, and analytical RP-HPLC run of Fraction 9 for isolation of isocereulide A (2). Figure S2: UPLC-ESI ${ }^{+}$-TOF-MS measurements of (a) the newly isolated isocereulide A (2) and (b) reference material of isocereulide A (2), obtained from [20]. Table S1: UPLC-ESI--TOF-MS data of cereulide (1) and isocereulide A (2). Figure S3: Structures of synthesized reference dipeptide units, with numbered atoms for assignment of NMR data. Figure S4: Massspectrometric fragmentation pattern (UPLC-ESI-TOF-MSe) of dipeptides (a) D-O-Leu-D-Ala, and (b) L-O-Val-L-Val present in cereulide (1), (c) L-O-Leu-L-Val in the predicted structure for isocereulide A [20], (d) and L-O-Ile-L-Val present in the newly elucidated structure of isocereulide A (2). Figure S5: UPLC-ESI ${ }^{-}$-TOF-MS chromatograms of acidic hydrolysis after chiral amino acid derivatization of (a) amino acid references L- and D-alanine and L- and D-valine, (b) cereulide (1), and (c) isocereulide A (2). Figure S6: UPLC-ESI--TOF-MS chromatograms of acidic hydrolysis after chiral $\alpha$-hydroxy acid derivatization of (a) $\alpha$-hydroxy acid references L- and D-O-valine, and L- and D-O-leucine with L- and D-O-isoleucine, (b) cereulide (2), (c) isocereulide A (1). Figure S7: ${ }^{1} \mathrm{H}-\mathrm{NMR}$ spectrum of $\mathbf{1}(500 \mathrm{MHz}$, $298 \mathrm{~K}$, Pyridine-d $\left.\mathrm{d}_{5}\right)$. Figure S8: ${ }^{1} \mathrm{H},{ }^{1} \mathrm{H}-\mathrm{COSY}-\mathrm{NMR}$ spectrum of $\mathbf{1}\left(500 \mathrm{MHz}, 298 \mathrm{~K}\right.$, Pyridine- $\left.\mathrm{d}_{5}\right)$. Figure S9: ${ }^{1} \mathrm{H},{ }^{13} \mathrm{C}-\mathrm{HSQC}-\mathrm{NMR}$ spectrum of $\mathbf{1}\left(500 \mathrm{MHz}, 125 \mathrm{MHz}, 298 \mathrm{~K}\right.$, Pyridine-d $\left.\mathrm{d}_{5}\right)$. Figure S10: ${ }^{1} \mathrm{H},{ }^{13} \mathrm{C}$-HMBC-NMR spectrum of $\mathbf{1}\left(500 \mathrm{MHz}, 125 \mathrm{MHz}, 298 \mathrm{~K}\right.$, Pyridine-d $\left.\mathrm{d}_{5}\right)$. Figure S11: ${ }^{13} \mathrm{C}-\mathrm{NMR}$ spectrum of 1 (125 MHz, $298 \mathrm{~K}$, Pyridine- $\left.\mathrm{d}_{5}\right)$. Figure S12: ${ }^{1} \mathrm{H}-\mathrm{NMR}$ spectrum of $2(500 \mathrm{MHz}, 298$ $\mathrm{K}$, Pyridine- $\left.\mathrm{d}_{5}\right)$. Figure S13A: ${ }^{1} \mathrm{H},{ }_{1}^{1} \mathrm{H}$-COSY-NMR spectrum of $2\left(500 \mathrm{MHz}, 298 \mathrm{~K}\right.$, Pyridine- $\left.\mathrm{d}_{5}\right)$. Figure S13B: Zoom ${ }^{1} \mathrm{H}_{1}{ }^{1} \mathrm{H}-\mathrm{COSY}$-NMR spectrum of $2\left(500 \mathrm{MHz}, 298 \mathrm{~K}\right.$, Pyridine-d $\left.\mathrm{d}_{5}\right)$. Figure S14: ${ }^{1} \mathrm{H},{ }^{13} \mathrm{C}-\mathrm{HSQC}-\mathrm{NMR}$ spectrum of $2\left(500 \mathrm{MHz}, 125 \mathrm{MHz}, 298 \mathrm{~K}\right.$, Pyridine- $\left.\mathrm{d}_{5}\right)$. Figure S15A: ${ }^{1} \mathrm{H}_{1}{ }^{13} \mathrm{C}-$ HMBC-NMR spectrum of 2 (500 MHz, $125 \mathrm{MHz}, 298 \mathrm{~K}$, Pyridine-d $)_{5}$. Figure S15B: Zoom ${ }^{1} \mathrm{H}^{13}{ }^{13} \mathrm{C}-$ HMBC-NMR spectrum of 2 (500 MHz, 125 MHz, 298 K, Pyridine-d ${ }_{5}$ ). Figure S16: DEPT135-NMR spectrum of 2 ( $125 \mathrm{MHz}, 298 \mathrm{~K}$, Pyridine- $\left.\mathrm{d}_{5}\right)$. Additionally, data on synthesis, purification, and NMR characterization of dipeptides and data on $\mathrm{MS}^{\mathrm{n}}$ sequencing are available.

Author Contributions: Manuscript Conception, V.W. and T.D.S.; syntheses of dipeptides, V.W.; NMR analysis, V.W.; mass spectrometry analysis, V.W.; isolation of (iso)cereulide, V.W.; cell culture, M.K.; methodology, V.W. and T.D.S.; writing-original draft preparation, V.W. and T.D.S.; writing-review and editing, T.D.S., M.K., M.E.-S. and T.F.H.; project administration, T.D.S. and M.E.-S.; funding acquisition, T.D.S., M.E.-S. and T.F.H. All authors have read and agreed to the published version of the manuscript.

Funding: This research (Project AiF 19659N) was supported by the German Ministry of Economics and Technology (via AiF) and the FEI (Forschungskreis der Ernährungsindustrie e.V., Bonn).

Data Availability Statement: The data presented in this study are available in the Supporting Information. 
Conflicts of Interest: The authors declare no conflict of interest. The funders had no role in the design of the study, in the collection, analyses, or interpretation of data; in the writing of the manuscript, or in the decision to publish the results.

Sample Availability: Sample of the compound cereulide is available from the authors.

\section{References}

1. Ehling-Schulz, M.; Lereclus, D.; Koehler, T.M. The Bacillus cereus Group: Bacillus Species with Pathogenic Potential. Microbiol. Spectr. 2019, 7. [CrossRef]

2. Ehling-Schulz, M.; Fricker, M.; Scherer, S. Baclus cereus, the causative agent of an emetic type of food-borne illness. Mol. Nutr. Food Res. 2004, 48, 479-487. [CrossRef]

3. Stenfors Arnesen, L.P.; Fagerlund, A.; Granum, P.E. From soil to gut: Bacillus cereus and its food poisoning toxins. FEMS Microbiol. Rev. 2008, 32, 579-606. [CrossRef]

4. $\quad$ Rouzeau-Szynalski, K.; Stollewerk, K.; Messelhausser, U.; Ehling-Schulz, M. Why be serious about emetic Bacillus cereus: Cereulide production and industrial challenges. Food Microbiol. 2020, 85, 103279. [CrossRef] [PubMed]

5. Agata, N.; Mori, M.; Ohta, M.; Suwan, S.; Ohtani, I.; Isobe, M. A novel dodecadepsipeptide, cereulide, isolated from Bacillus cereus causes vacuole formation in HEp-2 cells. FEMS Microbiol. Lett. 1994, 121, 31-34. [CrossRef] [PubMed]

6. Makarasen, A.; Yoza, K.; Isobe, M. Higher structure of cereulide, an emetic toxin from Bacillus cereus, and special comparison with valinomycin, an antibiotic from Streptomyces fulvissimus. Chem. Asian J. 2009, 4, 688-698. [CrossRef]

7. Suwan, S.; Lisobe, M.; Ohtani, I.; Agata, N.; Mori, M.; Ohta, M. Structure of cereulide, a cyclic dodecadepsipeptide toxin from Bacillus cereus, and studies on NMR characteristics of its alkali metal complexes including a conformational structure of the K+ complex. J. Chem. Soc. Perkin Trans. 1995, 1, 765-775. [CrossRef]

8. Marxen, S.; Stark, T.D.; Rutschle, A.; Lucking, G.; Frenzel, E.; Ehling-Schulz, M.; Scherer, S.; Hofmann, T. Depsipeptide Intermediates Interrogate Proposed Biosynthesis of Cereulide, the Emetic Toxin of Bacillus cereus. Sci. Rep. 2015, 5 , 10637. [CrossRef]

9. Ehling-Schulz, M.; Vukov, N.; Schulz, A.; Shaheen, R.; Andersson, M.; Märtlbauer, E.; Scherer, S. Identification and partial characterization of the nonribosomal peptide synthetase gene responsible for cereulide production in emetic Bacillus cereus. Appl. Environ. Microbiol. 2005, 71, 105-113. [CrossRef]

10. Ehling-Schulz, M.; Fricker, M.; Grallert, H.; Rieck, P.; Wagner, M.; Scherer, S. Cereulide synthetase gene cluster from emetic Bacillus cereus: Structure and location on a mega virulence plasmid related to Bacillus anthracis toxin plasmid pXO1. BMC Microbiol. 2006, 6, 20. [CrossRef]

11. Rasko, D.A.; Rosovitz, M.J.; Økstad, O.A.; Fouts, D.E.; Jiang, L.; Cer, R.Z.; Kolstø, A.-B.; Gill, S.R.; Ravel, J. Complete sequence analysis of novel plasmids from emetic and periodontal Bacillus cereus isolates reveals a common evolutionary history among the B. cereus-group plasmids, including Bacillus anthracis pXO1. J. Bacteriol. 2007, 189, 52-64. [CrossRef]

12. Lücking, G.; Rütschle, A.; Frenzel, E.; Ehling-Schulz, M.; Marxen, S.; Stark, T.D.; Hofmann, T.; Scherer, S. Ces locus embedded proteins control the non-ribosomal synthesis of the cereulide toxin in emetic Bacillus cereus on multiple levels. Front. Microbiol. 2015, 6, 1101. [CrossRef]

13. Gacek-Matthews, A.; Chromiková, Z.; Sulyok, M.; Lücking, G.; Barák, I.; Ehling-Schulz, M. Beyond Toxin Transport: Novel Role of ABC Transporter for Enzymatic Machinery of Cereulide NRPS Assembly Line. mBio 2020, 11, e01577-20. [CrossRef]

14. Dietrich, R.; Jessberger, N.; Ehling-Schulz, M.; Märtlbauer, E.; Granum, P.E. The Food Poisoning Toxins of Bacillus cereus. Toxins 2021, 13, 98. [CrossRef]

15. Magarvey, N.A.; Ehling-Schulz, M.; Walsh, C.T. Characterization of the cereulide NRPS alpha-hydroxy acid specifying modules: Activation of alpha-keto acids and chiral reduction on the assembly line. J. Am. Chem. Soc. 2006, 128, 10698-10699. [CrossRef]

16. Alonzo, D.A.; Magarvey, N.A.; Schmeing, T.M. Characterization of cereulide synthetase, a toxin-producing macromolecular machine. PLoS ONE 2015, 10, e0128569. [CrossRef] [PubMed]

17. Huguenin-Dezot, N.; Alonzo, D.A.; Heberlig, G.W.; Mahesh, M.; Nguyen, D.P.; Dornan, M.H.; Boddy, C.N.; Schmeing, T.M.; Chin, J.W. Trapping biosynthetic acyl-enzyme intermediates with encoded 2,3-diaminopropionic acid. Nature 2019, 565, $112-117$. [CrossRef]

18. Heberlig, G.W.; Boddy, C.N. Thioesterase from Cereulide Biosynthesis Is Responsible for Oligomerization and Macrocyclization of a Linear Tetradepsipeptide. J. Nat. Prod. 2020, 83, 1990-1997. [CrossRef]

19. Pitchayawasin, S.; Isobe, M.; Kuse, M.; Franz, T.; Agata, N.; Ohta, M. Molecular diversity of cereulide detected by means of nano-HPLC-ESI-Q-TOF-MS. Int. J. Mass Spectrom. 2004, 235, 123-129. [CrossRef]

20. Marxen, S.; Stark, T.D.; Frenzel, E.; Ruetschle, A.; Luecking, G.; Puerstinger, G.; Pohl, E.E.; Scherer, S.; Ehling-Schulz, M.; Hofmann, T. Chemodiversity of cereulide, the emetic toxin of Bacillus cereus. Anal. Bioanal. Chem. 2015, 407, 2439-2453. [CrossRef]

21. Naka, T.; Hattori, Y.; Takenaka, H.; Ohta, Y.; Kirihata, M.; Tanimori, S. Synthesis of the reported structure of homocereulide and its vacuolation assay. Bioorganic Med. Chem. Lett. 2019, 29, 734-739. [CrossRef] [PubMed]

22. Brückner, H.; Jaek, P.; Langer, M.; Godel, H. Liquid chromatographic determination of D-amino acids in cheese and cow milk. Implication of starter cultures, amino acid racemases, and rumen microorganisms on formation, and nutritional considerations. Amino Acids 1992, 2, 271-284. [PubMed] 
23. Hoye, T.R.; Jeffrey, C.S.; Shao, F. Mosher ester analysis for the determination of absolute configuration of stereogenic (chiral) carbinol carbons. Nat. Protoc. 2007, 2, 2451-2458. [CrossRef] [PubMed]

24. Frenzel, E.; Kranzler, M.; Stark, T.D.; Hofmann, T.; Ehling-Schulz, M. The endospore-forming pathogen Bacillus cereus exploits a small colony variant-based diversification strategy in response to aminoglycoside exposure. mBio 2015, 6, e01172-15. [CrossRef] 